\title{
MULHERES RURAIS: TECENDO NOVAS RELAÇÕES E RECONHECENDO DIREITOS
}

\author{
CELEC INA DE MARIA VERAS SALES \\ Universida de Federal do Ceará
}

\begin{abstract}
Resumo: A presença das mulheres rura is na produção agríc ola familiar é um fato. Mesmo na invisibilidade, não se pode negar que elas estão ocupando terras, plantando, colhendo, e cultivando o desejo de ter uma terra livre e usufruí-la com seu trabalho. Presentes na casa, no quintal, na roça e na luta pela terra, as mulheres tiveram ainda de lutar pelo direito de serem reconhecidas como trabalha doras. A emergência das mulheres rura is nos movimentos soc ia is proporcionou seu aparecimento como sujeito político, rompendo sua invisibilidade como trabalhadora. Nesse aprendizado e experimentação as mulheres rura is criaram seu próprio movimento, consolidado na década de 1980. Desde então realizam encontros nacionais, marchas e campanhas, cria ram coletivos de mulheres e conquista ram direitos. Os Coletivos de Mulheres estão vinculados à Federação de Trabalha dores da Agric ultura do Ceará (FETRAECE) ou ao Movimento dos Trabalhadores Rura is Sem Terra (MST) e constituem espaç os importantes de ressignific ação das ativida des produtivas das mulheres.
\end{abstract}

Palavras-chave: mulher rural; partic ipação política; grupos produtivos; movimentos socia is rura is.

No Ceará, em uma breve viagem a o campo, é possível visualizar meninas entre 8 e 12 a nos carregando á gua, a limentando os pequenos anima is, cuidando da casa e dos irmãos mais novos. Embora ela sestejam inseridas desde a infância no grupo de trabalho familiar, inclusive na roça, quando acompanham a família no período de colheita, elas crescem tendo de lutar para serem consideradas trabalhadoras rurais. Essa realida de se insere em uma luta mais ampla. ${ }^{1}$

O despertar pela luta coletiva do reconhecimento do trabalho das mulheres data da década de 1980. Um conjunto de eventos e de lutas das mulheres no mundo, no Brasil

Copyright $\odot 2006$ by Revista Estudos Feministas.

${ }^{1}$ Este artigo apresenta dados e reflexões de pesquisas desenvolvidas sobre mulher rural e relações de gênero e também de uma pesquisa em curso sobre esses temas. Esses dados foram coletados a través de entrevistas com mulheres rura is, lideranças do MST e da FEIRAECE, de levantamento de documentos de movimentos de mulheres e de dados obtidos nas ONGs que trabalham com mulheres rurais no Ceará. A pesquisa em andamento atende a todos os aspectos éticos pertinentes e foi aprovada pelo comitê de ética da UFC, cumprindo a exigência dessa universidade a partir de 2005. 
e, particularmente, no Ceará, no período de 1974 a 1985, chegou a o campo e marcou o percurso das mulheres rurais. As Conferências Mundiais, a a provação da Década da Mulher (1975-1985) e a instalação do Ano Internacional da Mulher em 1975 foram acontecimentos impulsionadores na luta pelos direitos das mulheres.

$\mathrm{Na}$ segunda metade da década de 1980, a luta das trabalhadoras rurais abre novos espaços políticos em que a fala dessas mulheres começa a ser franqueada. As principa is reivindicações foram pela sindicalização, documentação, direitos previdenciários e participação política.

Somente no ano de 1985 ocorreram 12 encontros de mulheres trabalhadoras rura is nas ma is diversas regiões do país. No a no seguinte, em novembro de 1986, as mulheres rura is realizaram em Brasília o primeiro Encontro Nacional de Trabalhadoras Rura is.

Nos anos posteriores, houve um maior envolvimento das trabalhadoras rurais em encontros, seminários, campanhas sobre violência contra mulheres, sobre mortalidade matema, sobre direitos constituciona is. Alguma sinic ia tivas isola das de grupose assesso rias, já existentes em tomo de trabalho e de organização das trabalhadoras rurais, unem-se aos novos movimentos emergentes.

Na década de 1990 inicia-se um período de adesão das instituições às desigualdades de gênero, com o enfoque na mulher. A Igreja Católica, por exemplo, com a Campanha da Fratemidade de 1990, cujo tema foi "Deus quer homem e mulher como companheiros, ig ua is nos direitos porque os dois são imagem e semelhança d'Ele", incentivou o debate sobre a condição da mulher, tanto na cidade como no campo.

Os eventos se multiplicam, passam a constituir acontecimentos importantes na vida das trabalhadoras rurais. Além do processo organizativo, as mulheres exercem 0 direito de falar, discordar, concordar, propor e reivindicar direitos.

A inserção das mulheres rura is no campo político (sindicatos, associações, movimentos sociais, partidos polític os) tem possibilitado um a prendizado coletivo. Para Pierre Bourdieu, "o campo político é entendido como campo de forças e como campo de lutas que têm em vista transformar a relação de forças que confere a este campo a sua estrutura em dado momento". ${ }^{2}$

O processo de organização das trabalhadoras rurais vai formando uma rede de comunic ação e signific ados, resultando na cria ção da Artic ula ção Na cional de Mulheres Trabalha doras Rura is em 1995.

No Nordeste, o movimento de mulheres rura is cresceu e acolheu multiplicidades de idéias expressas nos grupos organizados, entre eles o Movimento de Mulheres Camponesas (MMC), os Coletivos Esta dua is de Mulheres das Federações de Tra ba lha dores Rura is dos Estados, a Rede de Mulheres Trabalhadoras do Nordeste, o Movimento Interesta dual de Quebra deiras de Coco e o Movimento de Mulheres Tra balhadoras Rura is do Nordeste (MTR).

Ao ing ressa rem movimentos, as mulheres rura is cria m possib ilid a des de se a firma rem como portadoras de um saber-poderno campo da política, que lhes proporcione ta mbém repensar seu cotidiano, e isso tem ocorido no Ceará.

\section{Cartografia política das trabalhadoras rurais organizadas do Ceará}

A partic ipação das mulheres exige uma determinada competência, um acúmulo de capital político, masessa forma ção oc orre no cotidiano, na própria luta, como observa

${ }^{2}$ BOURDIEU, 1989, p. 164. 
Bourdieu: "a competência prática é adquirida em situação, na prática: o que é a dquirido é, inseparavelmente, o domínio prático da linguagem e o domínio prático das situações, que permitem produziro discurso adequado numa situação determinada". ${ }^{3}$

Como o campo político é também perpassa do pelas desigualdades de gênero, a competência a parece nesse campo como divisor dos tecnicamente competentes e dos que se representam por porta-vozes. ${ }^{4}$ As mulheres estão sempre incluídas entre os que prec isa m ser representa dos, entretanto, a quela s que estão inserida snos movimentos so c ia is têm demonstrado que as diferenças entre mulheres e homens não podem afirmar falta de competência política das mulheres.

A organização das Trabalhadoras Rurais do Ceará se expressa em dois grandes movimentos, o MSTe o movimento sindical (FETRAECE). O marco do movimento de mulheres, vincula do à FEIRAECE, foi o I Congresso de Mulheres Trabalha doras Rura is, rea liza do em 1991, quando se criou uma comissã o com o objetivo de mobiliza ras trabalhadoras rura is a se filia rem nos sindic atos.

Em 1993 a comissão se transforma no Coletivo Esta dual de Mulheres da Federação de Trabalhadores Rurais do Estado do Ceará. Outro evento de referência para as trabalhadoras rura is do Ceará foi sediar o I Encontro Latino-Americano e do Caribe da Mulher Trabalhadora Rural, rea liza do em Fortaleza, em 1996, com a participa ção de 237 delegadas de 21 países.

O ano de 1997 foi marcado pela Campanha de Documentação Nenhuma Trabalhadora Rural Sem Documento, lançada pela Articulação Nacional de Mulheres Trabalha doras Rura is (ANMTR).

As orga niza ções, os coletivos de tra balha doras rura is, incentiva ram a documenta ção e levantaram uma disc ussão sobre direitos, cidadania. As mulheres reconhecem que não basta serem produtoras, trabalhadoras; é preciso serem rec onhecidascomo tal. No C ea rá, a Campanha começou com a realização de um Seminário e com a Audiência Pública na Assembléia Legislativa do Ceará em 12 de agosto de 1998.

Uma outra conquista no Ceará, em 1998, foi a a prova ção da cota mínima de $30 \%$ de mulheres em todas as instâncias de direção e no congresso estadual da FETRAECE. Esse acontecimento representa um significativo avanço na luta contra a desigualdade de gênero no movimento sindical rural do Ceará.

O Coletivo Estadual de Mulheres da FETRAECE, entre 1993 e 2005, organizou nove coletivos regionais, o que corresponde a um por região, além de dezenas de comissões e coletivos munic ipa is orga nizados nos sind ic a tos.

O crescimento de grupos de mulheres e o aparecimento de lideranças no Ceará têm reafirmado o aprendizado das mulheres. Ao participar do campo político elas percebem que é preciso entrar no jogo, e jogar é tratar com o imprevisível, o novo, o desc onhecido. Não existe um modelo pronto para estabelecer uma negociação; é prec iso saber tratar com o inesperado, é desenvolver um pensar intempestivo, que dê vazão à criatividade, à espontaneidade.

A organização das trabalhadoras estimula suas lideranças a pensar sobre as desigualdades de gênero, e, a partir desse olhar, as trabalhadoras começam a discutir sobre a invisibilida de do seu trabalho na agricultura familiarcamponesa. Astrabalha doras rurais percebem que as atividades produtivas desenvolvidas no grupo familiar têm um signific ado econômico; não são simplesmente uma ajuda.

${ }^{3}$ BOURDIEU, 1983, p. 158.

${ }^{4}$ BOURDIEU, 1983. 
O MST tem também incorporado a discussão sobre as desigualdades de gênero na sua plataforma de luta. Por volta de 1997, o MST inclui em seus cursos de formação polític a os estudos de gênero. Segundo o Movimento, os estudos sobre as relações de gênero indicam como meta a construção de um novo homem e de uma nova mulher.

Essa disc ussão é efetivada na prátic a pelo MST quando, em 1999, a prova as linhas polític as sobre classe e gênero, em que são priorizadas a participação e a organização das mulheres na produção e na política. A concretização desse desejo de inclusão foi efetivada com a meta de criação de coletivos de gênero em todos os níveis de organização.

A operaciona liza ção dessas linhas na formação está prevista a tra vés da paridade na representação, da garantia do debate sobre gênero em toda atividade de formação e da recomendação de formar coletivos de mulheres.

A criação de coletivos, tanto pela FEIRAECE como pelo MST-CE, propic iou o enc ontro de lideranças e reflexões coletivas sobre as dificuldades específicas das trabalhadoras rurais que impedem o acesso delas aos diversos campos de decisão nos sindicatos, assentamentos e comunida des rura is. É ta mbém no interior d os coletivos de mulheres que as tra ba lha doras disc utem so bre sua a tivida de produtiva e percebem que é preciso destruir valores estabelecidos, para então descobrir a potência intema que leva à conquista de uma dimensão autônoma.

Se para algumas mulheres a inquietação inicial era possuir uma carteira para ter acesso aos direitos, que o sindicato prescreve aos trabalhadores, para outras significa tomar-se sócia-participante ou, a inda, assumir a luta dos sem-terra e a mplia rseus projetos, suas aspirações, passando a buscar como luta a inserção de outras mulheres nos movimentos. Mas, a o se inserir no sindic a to, elas se deparam com a hierarquia e dific uldade de inclusão das mulheres nas instâncias de poder das estruturas representa tivas.

Outro espaço de participação são os eventos políticos organizados pelo MST e pelo movimento sindical, como, por exemplo, os acampamentos, seminários, marchas e a tos públicos no Dia Internacional da Mulher. Em 2000 as trabalhadoras rura is do Ceará participaram da Marcha Mundial das Mulheres, realizando a Marcha das Margaridas.

Com a marcha de 2000 , as trabalhadoras conseguiram que os contratos e os títulos de terras da reforma agrária fossem em nome do homem e da mulher.

A participação das trabalha doras em movimentos socia is funciona como espaço de a prendizagem do jogo político, e a assimilação vai se dando no próprio exercício da luta, participando, discutindo, negociando. ${ }^{5}$

A Marcha das Margaridas em 2003 reivindica o a cesso à terra, a lém de um salário mínimo digno, saúde, com assistência integ ral à mulherdo ca mpo, e o fim da impunidade e da violência sexista.

\section{Conquistas e desafios das trabalhadoras rura is no campo produtivo}

A atividade da agricultura no Ceará, embora tenha importância econômica, concentra 0 maior índice de pobreza. Segundo Pedro Leite, ${ }^{6} 77 \%$ da população empregada na agricultura do estado está a baixo da linha da pobreza. Ainda predomina uma a gric ultura de subsistência, rudimentar, com baixo nível tec nológico, embora alguns setores e pólos isolados utilizem tecnologia modema.

${ }^{5}$ BO URDIEU, 1989.

${ }^{6}$ LEITE, 2005. 
Nessa realidade, mulheres trabalhadoras rura is do Ceará (pequenas a gric ultoras, posseiras, pescadoras a rtesanais, extrativistas, a rrendatárias, meeiras, parceiras, a ssa la ria da s rura is, sem-terra, a campa das, a ssenta das e indígenas) produzem a limentos e garantem a subsistência da família, a lém de se ocuparem também com o plantio de ervas medicinais e com o artesanato. Suas atividades se confundem com os diversos espaços de trabalho; elas, ao mesmo tempo em que cuidam da casa, carregam água, cuidam também dos pequenos anima is (galinhas, cabras e porcos) e das hortas. Além dessas atividades que se concentram principalmente na casa e no quintal, elas ainda desenvolvem trabalhos no roçado, principalmente no período do plantio e colheita.

Por não desenvolver todas as etapas do roçado, e por ser uma a tivida de liderada pelo homem adulto, esse trabalho é qualificado como ajuda, tanto no interior da família como nos sindicatos e órgãos públicos, o que inviabilizou durante muito tempo o reconhec imento das mulheres como trabalhadoras e, conseqüentemente, a garantia de seus direitos socia is.

Emb ora as mulheres estivessem presentes, ou mesmo lidera do luta s pela conquista da terra, elas não eram beneficiadas pelos Planos e Projetos de Reforma Agrária. Em 2003, a tra vés da Porta ria 981/2003, do Instituto Na cional de Coloniza ção e Reforma Agrária (INCRA), toma-se obrigatória a titulação da terra em nome do homem e da mulher, em situa ções de casamento ou união estável.

Para reparar as desigualdades de gênero, no que diz respeito aos direitos das trabalhadoras rurais, foram criados alguns projeto $\mathrm{s}^{7}$ que contemplam demandas dessas mulheres.

A a mpliação signific a tiva da cidadania feminina no campo desencadeou-se principalmente com a Constituição de 1988 , quando no artigo $226, \S 5^{\circ}$, foi reconhecida a igualdade entre homense mulheres na fa mília, e no artigo 189, parágrafo únic o, esta belecida a igualdade de direitos entre homense mulheres na obtenção de título de domínio ou de conc essã o de uso de terras para fins de reforma a grá ria. Essa sconquista s sã o funda menta is, expressam a luta das mulheres, no enta nto elas esbarram em outros obstáculos, como a falta de documentose escolaridade. A dificulda de de lidarcom a tividades do mundo público, como abrirconta bancária, porexemplo, é reforçada pelaspráticase costumes sexistas, que colaboram com a perpetuação da subordinação das mulheres rura is.

O reconhecimento legal das mulheres na produção da agricultura familiar é um grande passo, mas além das leis é necessário um conjunto de ações paralelas que empoderem as mulheres, para que possam usufruir os direitos conquistados. A burocratização que envolve os programas de crédito inviabiliza o a cesso das mulheres.

O MST do Ceará acompanha cerca de 48 grupos de produção no estado, dos quais 30 grupos estão constituídos e 18 em formação. As a tividades produtivas desenvolvida s por esses grupos sã o: horta coletiva; artesa na to; c ria ção de ga linha; cria ção de cabra/ovelha; fabricação de xaropes e sabonetes naturais; criação de tilápia em cativeiro; minifábrica de rapadura e doce de caju. A comercia lizaçã o desses produtos é realiza da nas feiras da reforma agrária, no próprio assentamento, na sede do município ou nos espa ç os de a tivid a des do MST. Desses g rup os, a pena s do is utiliza $\mathrm{m}$ rec urso s extemos. Nenhum deles pleiteou o PRONAF Mulher.

\footnotetext{
${ }^{7}$ São os ca sos do Projeto Dom Helderdestina do ao semi-árido, cuja missão é contribuir pa ra o desenvolvimento humano-local-sustentável-integrado, fortalecer a cidadania e as perspectivas de gênero, geração e etnia, do Programa de Igualdade de Gênero, Raça e Etnia do Ministério do Desenvolvimento Agrário (MDA) e da linha de crédito do Programa Nacional de Fortalecimento da Agricultura Familiar (PRONAF) denominada Pronaf Mulher.
} 
Observa-se que, "nas áreas de semi-árido de agricultura tradicional, a relação entre mercado e a agricultura familia ré perversa e inviável, não sendo possível competir com o mercado globalizado". ${ }^{8}$ No caso das mulheres, a situação é mais grave, pois, a lém de muitas delas não possuírem o título da terra e/ou documentação, o seu trabalho é desvalorizado e a decisão da comercialização é quase sempre centrada nos homens.

A partic ipação das mulheres rura is em grupos de produção, coletivos, ocupação da terra e eventos polític os tem suscitado novos processos e reflexões sobre sua própria situação e aquilo que se passa em tomo delas.

As experimentações no campo produtivo estão sendo iniciadas no Ceará pelos grupos de mulheres, principalmente a queles a ssessora dos pelas ONGs ESPLAR (Centro de Pesquisa e Assessoria) e CETRA (Centro de Estudos do Trabalho e de Assessoria a o Trabalhador), que trabalham na perspectiva de oferecer às mulheres altemativas de geração de renda. Os grupos assessorados pela ESPLAR são os coletivos regiona is de mulheres da FEIRAECE do Sertão Central e da Zona Norte, comissões de mulheres de Sindicatos de Trabalhadores Rurais, grupos de mulheres rura is de assentamentos rurais, grupo de mulheres fiadeiras e grupo de mulheres apicultoras e caprinocultoras.

O CEIRA também trabalha com projetos de inclusão de mulheres no sentido de fortalecer as organizações das mulheres, visando à eqüidade da participação e das oportunidadesno processo de desenvolvimento. Os projetos seguem quatro eixos temáticos de traba lho: "Terra, água e a groec ologia"; "Educação e ação a mbiental"; "Soc ioeconomia solidária"; e "Gênero e cidadania".

\section{Considerações fina is}

Os grupos de produção, formados por mulheres rura is no Ceará, em geral, são antecedidos por uma formação política. Quando as mulheres começam a se organizar em comissões, em coletivos, elas perc ebem que, embora não tenham renda, desenvolvem a tivida des produtivas semelhantes às dos homens. Éta mbém no g rupo que elas começam a rever suas relações e a perceber as desigualdades entre homens e mulheres.

A partic ipa ção em movimentos soc ia is incentiva as mulheres ma is a tuantes a romper com a rígida divisão de papéis, com o lugar já predeterminado na família, no trabalho, e a ocupar espaço no campo político.

Os movimentos socia is, como espaço inovador das relações de poder, criam e recriam novas formas de reivindic are de esta belecer relações com o poder instituc ional. No entanto, eles não se isentam de posições tra dic iona is de desigualdades de gênero.

Nesse sentido, a participação política é um aprendizado coletivo que se redefine no interior dos próprios movimentos.

A partic ipação das mulheres nos movimentos socia is é ta mbém um espaço de luta, de contestação dos dispositivos de poder que organizam saberes dominantes, mas não deixa de seruma possibilida de de escapardo controle familia re de vivencia routros códigos.

A partir do envolvimento em movimentos soc ia is as mulheres se sentem forta lec idas e começam a produzir seus processos de reação à sub missão, passam a reconhecerque possuem um determinado ca pital espec ífic o sufic iente para formarum grupo de produção, ter uma renda. Depois de experimentar uma a tividade produtiva rentável, as mulheres não são a s mesmas, já não se sentem tão prisioneiras, estão ma is a bertas à s multiplic ida des do mundo, sonham com liberda de e, assim, conta giam outras mulheres, a fetando e sendo a fetadas por esses desejos.

${ }^{8}$ Ana Paula PORTEШA, Camem SILVA e Simone FERREIRA, 2004, p. 71. 


\title{
Referências bibliográficas
}

BOURDIEU, Pierre. Sociologia. São Paulo: Ática, 1983.

. O poder simbólico. Lisboa: Difel; Rio de Janeiro: Bertrand Brasil, 1989.

LEITE, Pedro Sisnando. Em busca do desenvolvimenrto rural do Ceará. Ceará: SEAGRI-CE, 2005. Disponível em: http://www.sea gri.ce.gov.br. Acesso em: dez. 2005.

PORTELLA, Ana Paula; SILVA, Carmem; FERREIRA, Simone. Mulher e trabalho na a gric ultura familiar. Recife: SOS CORPO - Gênero e Cidadania, 2004.

SALES, Celecina de Maria Veras. Conflito no feminino: trajetórias políticas de mulheres no campo. 1995. Dissertação (Mestra do em Sociologia) - Programa de Pós-Graduação em Sociologia, Universidade Federal do Ceará, Fortaleza.

. "Gênero e MST". In: AMARAL, Célia G. (Org.). Teoria e práxis dos enfoques de gênero. Sa Iva dor: Editora REDOR; Forta leza: NEGIF/UFC, 2004. p. 101-117.

\begin{abstract}
Rural Women: Establishment of New Relations and Recognition of Rights
Abstract: Women are effectively engaged in family agricultural production. In spite of certain invisibility, women are occupying fields, planting and harvesting. At the same time, they are longing for a free land where they can work. They have always been active at home, in the backyards, in the small subsistence farms and now they are struggling to being recognized as rural workers. The involvement of rural women in social movements has conferred on them the status of politic al beings and as a result they a re not invisible a ny longer. In the process of ac tive experimentation and learning they founded their own social movement that has become well established since the 1980 decade. Since then, they have organized national meetings, campaigns and created organizations called "Women Collectives." These organizations are connected to either the Federation of Agricultural Workers in Ceará (FETRAECE - CE) or to the MST (Movement of Landless Workers). They represent important opportunities for giving new meanings to the productive activities of women.
\end{abstract}

Key words: Rural Women; Politic al Participation; Produc tive Groups; Rural Social Movements. 